\title{
COMMISSION 6: ASTRONOMICAL TELEGRAMS
} (TELEGRAMMES ASTRONOMIQUES)

\author{
PRESIDENT: Richard M. West \\ VICE-PRESIDENT: Brian G. Marsden \\ SECRETARY: Daniel W. E. Green \\ ORGANIZING COMMITTEE: S. Nakano, E. Roemer, R.M. West
}

\section{Report of Business Meeting at 16:00, 15 August 2000}

Members present: K. Aksnes, D. W. E. Green, B. G. Marsden, S. Nakano, D. J. Tholen, M. Tsvetkov, R. M. West

President West welcomed the 18 other persons present and read the Agenda for this business meeting of Commission 6. He then expressed his pleasure at the availability of the $I A U$ Circulars to nonpaying subscribers on the World Wide Web site of the Central Bureau for Astronomical Telegrams (CBAT) - an accomplishment begun at the time of the last General Assembly in Kyoto - to which CBAT Associate Director D. W. E. Green added that $I A U C s$ are posted anywhere from immediately to several days later, the usual delay of 1-4 days being in respect to those hundreds of paying subscribers. In his report for the past triennium, West expressed thanks to the CBAT staff on behalf of the astronomical community for their service, noting the usefulness of much of the information on IAUCs. Green prepared a majority of the IAUCs during the previous triennium, with CBAT Director B. G. Marsden preparing most of the remainder; Minor Planet Center (MPC) Associate Director G. V. Williams served as CBAT webmaster and has thus been responsible for the Web CS dissemination of the IAU Circulars.

In his triennial report, Marsden noted that $I A U C s$ are available in dvi or postscript form via the CBAT website, but that subscribers to the printed IAUCs are down from a pre-Internet count of $\sim 700$ to just under 300 now, plus 500 electronic subscribers. $\mathrm{He}$ added that line charges are still necessary to pay expenses, including CBAT staff salaries.

Marsden remarked on the necessity of establishing criteria in 1997 September for prospective discoverers of novae and supernovae, as a result of the increasingly ready access of both professional and amateur astronomers to the Internet and the problems caused by rapid communications of unconfirmed reports (see $I A U C 6736,6737,6739$ ). He reported that the new procedures (in which observers must supply three of four types of information before designation and announcement can formally be made on an IAUC) have been working well in the past triennium. He added that two nights of observation showing cometary activity are now also preferred before announcement of a new comet. The CBAT has been collaborating closely with the American Association of Variable Star Observers for some years on bright nova and supernova discovery reports, as well.

West then announced that, following Marsden's decision to step down as CBAT Director at the end of the current General Assembly, after nearly 33 years in that position, Green had been chosen by Commission 6 to succeed Marsden. West then introduced Green as the new CBAT Director, and Green explained that there should be little visible change in the way that the CBAT is run, since he has edited the large majority of IAUCs for some 13 years as Associate Director. Green's involvement with preparing IAUCs goes back to the summer of 1978, when he began working with Marsden as a student; he began working 
fulltime with the CBAT and Minor Planet Center activities in 1980. Green noted that one on-going project is preparing old $I A U C s$ for display online, with about 2400 or so of the early Circulars yet to be edited; his son, Andrew, has recently been working on this project.

Marsden related that Carl W. Hergenrother (University of Arizona) and Elizabeth Waagen (AAVSO) were temporarily helping in the preparation of $I A U C s$ during the Manchester General Assembly, though Green was able to issue IAUC 7477 remotely from Manchester.

In Division III during the Manchester General Assembly, the "Small Bodies Names Committee" (SBNC) changed its name to "Committee on Small Bodies Nomenclature" (CSBN), and its membership was increased from 11 to 13. Marsden had been a member of the SBNC as Director of both the CBAT and the MPC, but West noted the need for the new CBAT Director to continue on this committee due to the historical involvement of the CBAT in the designation and naming of comets via the IAUCs, and he added that Commission 6 should recommend to the Executive Committee that Green be added to the CSBN for comets only. This was seconded by Pam Kilmartin, the newly elected Chair of the CSBN, who said that it is "essential" for the CBAT Director to be a member of this committee. This recommendation to the Executive Committee was approved.

Commission 6 members had asked about the continued need for printed IAUCs, to which Green stated that there was still a large subscriber demand for the printed Circulars, and that the subscriptions paid for the cost of printing. D. Tholen observed that the small postcard-sized IAUCs do not take up much library shelf space. It was also remarked that the Internet cannot always be accessed from any given site, and that the printed IAUCs can be very useful at such times. Therefore, it was agreed that printed $I A U C s$, which also serve as the official version of the Circulars (the e-mailed version having ASCII-only type and thus unable to accommodate symbols, subscripts, diacritical marks, etc.), will continue for the foreseeable future.

After some discussion that it might be useful to have a collection of published IAUCs in a larger format, it was considered that two volumes of these should be produced per year. The possibility of issuing collections of IAUCs on CD-ROM was dismissed when Williams noted the problems with searching (which tends to be platform-specific).

West asked how many in attendance actually accessed the IAUCs from the web, and only one answered affirmatively. Williams provides the following web statistics regarding access to IAUCs: in the 8-week period ending 2000 Aug. 13, there were 123049 single accesses to the $I A U C s$ on the CBAT website, for an average of 15381 accesses per week (the weekly range being $8812-22973$ ).

Tholen asked whether, with so many old SOHO comets being reported in recent months, it was prudent to continue announcing them on IAUCs, especially given that only one SOHO comet discovery has ever been observed by ground based observers. It was agreed that such SOHO comets could be announced on Minor Planet Electronic Circulars $(M P E C s)$ by the Minor Planet Center and then later collected into tables on IAUCs -but it was noted that the record of new comet discoveries and designations needs to be published on IAUCs. The policy for other comets will continue to be that announcement is given first (with the new designations) on IAUCs, with additional astrometry and perhaps more detailed orbital elements given immediately afterward on MPECs.

Mattei noted that the material on IAUCs is highly respected in the astronomical community, because of the care that the CBAT uses before announcing new discoveries. She noted a significant waste of large-telescope observing time concerning unchecked reports that float rapidly around on various Internet channels (both via e-mail and various websites), and she added that the CBAT policy of expressing caution while waiting for many confirming reports before announcing a new supernova or nova is a good policy. Mattei further noted the helpful agreement of N. N. Samus (Sternberg Astronomical Institute, Moscow), on behalf of IAU Commission 27, in rapidly supplying permanent variable-star designations for newly discovered novae to the CBAT for inclusion on IAUCs, a policy effective in April 1999. 
West stated that it was time for him to step down as Commission 6 President after two terms, and he put forth the proposed slate of new officers for the coming triennium, namely, Marsden as President and Kaare Aksnes (Norway) as Vice President, with the Organizing Committee consisting of A. C. Gilmore (New Zealand), Green (as CBAT Director), S. Nakano (Japan), E. Roemer (USA) and West (by custom, as past President).

There were no new nominations, and the officers and Organizing Committee members were accepted by unanimous vote. New members elected to Commission 6 were Williams (USA), J. Tichá (Czech Republic), G. Apostolovska (Macedonia), H. Yamaoka (Japan), and Mattei (USA). It was proposed and unanimously accepted that Marsden would carry the title of "Director Emeritus" of CBAT, and appreciation was acknowledged by professional and amateur astronomers to Marsden for his many years of service.

R. West

President of the Commission 